\title{
ADEQUAÇÃO DE DIETAS PARA CRIAÇÃO DE ADULTOS DE CHRYSOPERLA EXTERNA (HAGEN) (NEUROPTERA: CHRYSOPIDAE)
}

\author{
L.G.A. Pessoa ${ }^{1}$, S. de Freitas ${ }^{2}$, E. de S. Loureiro ${ }^{1}$
}

${ }^{1}$ Universidade Federal de Mato Grosso do Sul, CP 112, CEP 79560-000, Chapadão do Sul, MS, Brasil. E-mail: gugamorim@nin.ufms.br

\section{RESUMO}

\begin{abstract}
Objetivou-se avaliar a resposta de adultos de Chrysoperla externa alimentados com diferentes dietas. Adultos da geração $\mathrm{F}_{2}$ foram individualizados em gaiolas de PVC e alimentados com lêvedo de cerveja +mel (dieta padrão), lêvedo de cana + mel e extrato de soja + mel (1:1). Os bioensaios foram conduzidos a $25 \pm 2^{\circ} \mathrm{C}, 60 \pm 10 \%$ de UR e fotofase de 12 horas. Avaliou-se, durante 60 dias, o período de pré-oviposição, oviposição diária e total, viabilidade dos ovos e índice de aproveitamento (IA). Verificou-se que a dieta composta por lêvedo de cana + mel foi semelhante à dieta padrão. Também se verificou que as dietas não interferiram sobre o período de pré-oviposição e a viabilidade dos ovos. Apenas para os insetos alimentados com extrato de soja + mel observou-se redução significativa na oviposição diária, oviposição total e índice de aproveitamento. A dieta composta por lêvedo de cana + mel foi adequada para criação de adultos de C. externa podendo ser utilizada em substituição à dieta composta por lêvedo de cerveja + mel.
\end{abstract}

PALAVRAS-CHAVE: Controle biológico, crisopídeo, criação massal.

\section{ABSTRACT}

SUITABILITY OF DIETS FOR REARING OF ADULTS OF CHRYSOPERLA EXTERNA (HAGEN) (NEUROPTERA: CHRYSOPIDAE). This work was aimed to evaluate the response of adults of Chrysoperla externa fed different diets. Adults from F2 offspring were individualized in PVC cages and received food, formed by yeast + honey (standard diet), sugarcane yeast + honey and soy extract + honey, at 1:1. The bioassays were conducted at $25 \pm 2{ }^{\circ} \mathrm{C}, 60 \pm 10 \%$ of RH and 12-hour photophase. Over a period of 60 days, evaluations were made of the period of pre-oviposition, daily and total oviposition, the viability of the eggs and the exploitation index (EI). It was verified that the diet containing sugarcane yeast + honey was similar to the standard diet. It was also verified that no diet interfered with the pre-oviposition and egg viability. Only for the insects fed soy extract + honey was there a significant reduction in the values of the daily and total oviposition and the exploitation index. Under the tested conditions and proportions, the diet formed by sugarcane yeast + honey was suitable for the rearing of C. externa adults, and can be used to replace the diet formed by yeast + honey.

KEY WORDS: Biological control, green lacewing, mass rearing.

A maioria dos insetos pertencentes à ordem Neuroptera é predadora, destacando-se as famílias Chrysopidae e Hemerobiidae como as mais importantes por se alimentarem de diversas pragas agrícolas (Agnew et al., 1981). Dentre os insetos encontrados nessas duas famílias, os crisopídeos são predadores que exercem importante papel no controle biológico de artrópodes fitófagos em muitas culturas de interesse econômico, estando associados a artrópodes-praga que apresentam incidência estacional ou não (VelLoso et al., 1999; FigUeIRA et al., 2000; FREITAS, 2001). São polífagos, apresentam vasta distribuição geográfica, alta capacidade de busca e voracidade e elevado potencial reprodutivo (MAIA et al., 2000).

A criação massal e eficiente desses predadores em laboratório depende de fatores extrínsecos e intrínsecos. Dentre os extrínsecos pode-se citar as técnicas utilizadas para multiplicação dos insetos, materiais empregados, a manipulação dos insetos nas diversas fases de desenvolvimento, o controle de qualidade e os custos de produção. Os intrínsecos estão relacionados à fisiologia do inseto como a adaptabilidade à dieta, potencial

${ }^{2}$ Universidade Estadual Paulista, Faculdade de Ciências Agrárias e Veterinárias, Departamento de Fitossanidade, Jaboticabal, SP, Brasil. 
reprodutivo, a fecundidade e fertilidade (CARVALHO; SOUZA, 2000; 2009). O estabelecimento de um programa de controle biológico utilizando esse grupo de insetos passa por várias fases e, uma delas, é a produção de um grande número de indivíduos de forma eficaz e barata. Para isso, faz-se necessária a elaboração de uma dieta que forneça aos insetos todos os nutrientes necessários a sua manutenção e que mantenham altas porcentagens de fecundidade e de fertilidade.

Adultos de crisopídeos são criados de forma eficaz com dieta à base de lêvedo de cerveja + mel (FREITAS, 2001), a qual provém os aminoácidos necessários à manutenção da fecundidade e fertilidade. Porém, alguns alimentos apresentam potencial para serem utilizados em criações massais de adultos desses insetos em substituição ao lêvedo de cerveja. Assim, este trabalho teve por objetivo avaliar a adequação de diferentes dietas para criação de adultos de Chrysoperla externa (Hagen) (Neuroptera: Chrysopidae).

Adultos de crisopídeos foram coletados em pomar de macadâmia e levados ao laboratório onde, após a triagem e identificação, adultos de C. externa foram acondicionados em gaiolas cilíndricas de cloreto de polivinila (PVC) de $10 \mathrm{~cm}$ de diâmetro por $23 \mathrm{~cm}$ de altura. Larvas oriundas de insetos da primeira geração foram alimentadas com ovos de Sitotroga cerealella (Oliver) (Lepidoptera: Gelechiidae) de acordo com a metodologia proposta por Freitas (2001). Para os bioensaios foram utilizados adultos da geração $\mathrm{F}_{2}$, os quais receberam alimento à base de lêvedo de cerveja (em pó) + mel (dieta padrão), lêvedo de cana (desidratada) + mel e extrato de soja (em pó) + mel, todos em partes iguais.

Os experimentos foram conduzidos em sala climatizada a $25 \pm 2^{\circ} \mathrm{C}, 60 \pm 10 \%$ de UR e fotofase de 12 horas. Foi avaliado, durante 60 dias, o período de pré-oviposição, a oviposição diária e total, bem como a viabilidade semanal dos ovos produzidos por esses insetos. Para avaliação da viabilidade dos ovos, uma alíquota de 20 ovos foi coletada de cada gaiola. Além desses parâmetros, também foi utilizado o índice de aproveitamento (IA), o qual leva em consideração a capacidade de oviposição total, a viabilidade média dos ovos e o período de oviposição, proposto por PESSOA et al. (2004). Esse índice permite avaliar o número de ovos viáveis produzidos diariamente por cada fêmea, constituindo-se uma avaliação mais eficiente do que a determinação distinta dos parâmetros capacidade de oviposição total e viabilidade média dos ovos.

Foram utilizadas nove repetições, cada uma constituída por um casal individualizado em uma gaiolas de PVC em delineamento inteiramente casualizado. Os dados referentes à oviposição diária e total e o IA foram transformados para $(x+0,5)^{1 / 2}$. Aqueles referentes à viabilidade dos ovos produzidos pelos insetos foram transformados para arco-seno $(\mathrm{x} / 100)^{1 / 2}$. Efetuou-se a análise de variância e o teste de agrupamento de médias de Tukey a $5 \%$ de probabilidade.

Observando os resultados de todos os parâmetros avaliados, verificou-se que a dieta composta por lêvedo decana+mel foi significativamente semelhante à dieta padrão. Também se verificou que nenhuma dieta interferiu significativamente sobre o período de pré-oviposição e a viabilidade dos ovos. Apenas para os insetos alimentados com extrato de soja + mel observou-se redução significativa na oviposição diária, oviposição total e índice de aproveitamento (Tabela 1).

Crescimento, desenvolvimento e reprodução dos insetos estão diretamente correlacionados com a quantidade e qualidade do alimento ingerido. Assim, a ingestão do alimento dependerá de vários fatores como ser digerível e assimilável (PARRA, 1991).

Os crisopídeos são considerados insetos glicopolinívoros, ou seja, alimentam-se de néctar, pólen e/ou "honeydew" (Albuquerque, 2009). De acordo com GARCiA (1991), crisopídeos do gênero Chrysoperla Steinmann necessitam da associação com leveduras ou bactérias simbiontes para provisão de aminoácidos a partir de dietas a base de néctar e secreções açucaradas. Ainda, essa associação favorece a sintetização de compostos essenciais para produção de ovos por insetos predadores, como os crisopídeos.

Tabela 1 - Parâmetros biológicos (Média \pm EP) de adultos de Chrysoperla externa alimentada com diferentes dietas.

\begin{tabular}{lccccc}
\hline Tratamentos & $\begin{array}{c}\text { Período de pré- } \\
\text { oviposição }\end{array}$ & $\begin{array}{c}\text { Oviposição } \\
\text { diária }\end{array}$ & $\begin{array}{c}\text { Oviposição } \\
\text { total }\end{array}$ & $\begin{array}{c}\text { Viabilidade dos } \\
\text { ovos }\end{array}$ & $\begin{array}{c}\text { Índice de } \\
\text { aproveitamento }\end{array}$ \\
\hline Lêvedo de cerveja & $4,8 \pm 0,30 \mathrm{a}$ & $14,1 \pm 1,03 \mathrm{a}$ & $576,9 \pm 42,45 \mathrm{a}$ & $93,3 \pm 1,70 \mathrm{a}$ & $13,1 \pm 1,01 \mathrm{a}$ \\
Lêvedo de cana & $5,1 \pm 0,35 \mathrm{a}$ & $15,0 \pm 0,66 \mathrm{a}$ & $710,2 \pm 52,02 \mathrm{a}$ & $93,1 \pm 4,40 \mathrm{a}$ & $13,2 \pm 0,91 \mathrm{a}$ \\
Extrato de soja & $6,0 \pm 0,95 \mathrm{a}$ & $5,5 \pm 0,52 \mathrm{~b}$ & $232,3 \pm 28,52 \mathrm{~b}$ & $89,0 \pm 2,24 \mathrm{a}$ & $5,2 \pm 0,45 \mathrm{~b}$ \\
\hline CV $(\%)$ & 31,72 & 22,11 & 26,85 & 11,05 & 22,84
\end{tabular}

Médias seguidas pela mesma letra minúscula na coluna não diferem significativamente entre si pelo teste de Tukey $(\mathrm{P}<0,05)$. 
De acordo com CARvalHo; SouZA (2000; 2009), uma dieta de baixo custo, para ser considerada adequada, deverá conter uma levedura (que apresente alto teor proteico, fundamental para oogênese e espermatogênese, permitindo assim maior fecundidade) associada a uma fonte de carboidrato, no caso o mel, que, devido a seu caráter higroscópico, manterá a textura e consistência adequadas para os crisopídeos e, segundo PARRA (1991), além de estar disponível, ser digerível e assimilável pelo inseto, uma dieta também precisa ser aceita. Assim, a consistência e textura proporcionadas pela mistura de leveduras desidratadas e mel pode ser considerada um estímulo a mais para a aceitação da dieta pelos crisopídeos.

Observando os resultados obtidos verificou-se que, além da dieta padrão, aquela composta por lêvedo de cana e mel, na proporção testada, foi adequada a criação de adultos de C. externa, uma vez que ela foi aceita pelos insetos e não houve interferência significativa sobre a oogênese e espermatogênese, permitindo a manutenção da fecundidade, atestada pelos resultados observados do índice de aproveitamento.

O extrato de soja em pó é um alimento de baixo custo que poderia ser incorporado em dietas de insetos e, segundo RoDRIGUEs et al. (2002), apresenta teores de proteínas em torno de $40 \%$. Apesar de ser um alimento rico em proteínas, os crisopídeos provavelmente não consigam utilizá-las plenamente, provavelmente devido a necessidade da associação simbiótica com as leveduras para provimento de aminoácidos, como sugerido por GARCIA (1991). Além disso, de acordo com CARvalHo; Souza (2000, 2009), alguns ingredientes incorporados à dieta eque apresentem elevado teor proteico podem interferir negativamente na biologia e reprodução de algumas espécies de crisopídeos.

Coclui-se que, nas condições e proporções testadas, a dieta composta por lêvedo de cana (desidratada) + mel é adequada para criação de adultos de C. externa podendo ser utilizada em substituição à dieta padrão composta por lêvedo de cerveja (em pó) + mel.

\section{REFERÊNCIAS}

ALBUQUERQUE, S.A. Crisopídeos (Neuroptera: Chrysopidae). In: PANIZZI, A.R.; PARRA, J.R.P. (Ed.). Bioecologia e nutrição de insetos: base para o manejo integrado de pragas. Brasília: Embrapa Informação Tecnológica, 2009. Cap. 23, p.969-1022.

AGNEW, C.W.; STERLING, W.L.; DEAN, D.A. Notes on the Chrysopidae and Hemerobiidae of Eastern Texas with for their identification. Southwestern Entomologist, v.4, p.1-20, 1981.
CARVALHO, C.F.; SOUZA, B. Métodos de criação e produção de crisopídeos. In: BUENO, V.H.P. (Ed.). Controle biológico de pragas: produção massal e controle de qualidade. Lavras: UFLA, 2000. Cap. 6, p.91-109.

CARVALHO, C.F.; SOUZA, B. Métodos de criação e produção de crisopídeos. In: BUENO, V.H.P. (Ed.). Controle biológico de pragas: produção massal e controle de qualidade. 2.ed. Lavras: UFLA, 2009. Cap. 3, p.77-115.

FIGUEIRA, L.K.; CARVALHO, C.F.; SOUZA, B. Biologia e exigências térmicas de Chrysoperla externa (Hagen,1861) (Neuroptera: Chrysopidae) alimentada com ovos de Alabama argillacea (Hübner, 1818) (Lepidoptera: Noctuidae). Ciência e Agrotecnologia, v.24, n.2, p.319-326, 2000.

FREITAS, S de. Criação de crisopídeos (bicho lixeiro) em laboratório. Jaboticabal: Funep, 2001. 20p.

GARCIA, M.A. Ecologia nutricional de parasitóides e predadores terrestres. In: PANIZZI, A.R.; PARRA, J.R.P. (Ed.). Ecologia nutricional de insetos e suas implicações no manejo de pragas. São Paulo: Editora Manole, 1991. Cap. 8, p.289-311.

MAIA, W.J.M.S.; CARVALHO, C.F.; SOUZA, B. Exigências térmicas de Chrysoperla externa (Hagen, 1861) (Neuroptera: Chrysopidae) alimentada com Schizaphis graminum (Rondani, 1852) (Hemiptera: Aphididae) em condições de laboratório. Ciência e Agrotecnologia, v.24, n.1, p.81-86, 2000.

PARRA, J.R.P. Consumo e utilização de alimentos por insetos. In: PANIZZI, A.R.; PARRA, J.R.P. (Ed.). Ecologia nutricional de insetos e suas implicações no manejo de pragas. São Paulo: Editora Manole, 1991. Cap. 2, p.289-311.

PESSOA, L.G.A.; FREITAS, S. de; GARDIM, S.; RODRIGUES, K.C. Potencial reprodutivo de adultos de Chrysoperla raimundoi Freitas \& Penny (Neuroptera: Chrysopidae) em função da alimentação larval. Arquivos do Instituto Biológico, São Paulo, v.71, n.4, p.519-521, 2004.

RODRIGUES, P.B.; ROSTAGNO, H.S.; ALBINO, L.F.T.; GOMES, P.C.; SANTANA, R.T.; NUNES, R.V. Aminoácidos digestíveis verdadeiros da soja e subprodutos, determinados com galos cecectomizados. Revista Brasileira de Zootecnia, v.31, n.2, p.970-981, 2002.

VELLOSO, A.H.P.P.; RIGITANO, R.L.O.; CARVALHO, G.A.; CARVALHO, C.F. Efeitos de compostos reguladores de crescimento de insetos sobre larvas e adultos de Chrysoperla externa (Hagen, 1861) (Neuroptera: Chrysopidae). Ciência e Agrotecnologia, v.23, n.1, p.96-101, 1999.

Recebido em 5/10/09

Aceito em 29/10/10 